\title{
Physiological and biochemical characteristics of some therophyllous species of the Ficus genus in water stress conditions
}

\author{
Oksana Grebennikova*, Ruslana Pilkevich \\ The Nikitsky Botanical Gardens - National Scientific Center of the RAS, 298648, Yalta, Russian \\ Federation
}

\begin{abstract}
The relevance of the search for physiological and biochemical parameters associated with the implementation of plant adaptation mechanisms to the combined action of high temperatures and water stress is dictated by frequent summer droughts in southern regions. For this purpose, every month during the dry period under the conditions of a laboratory experiment a number of physiological and biochemical parameters were determined in the leaves of species F. palmata, F. virgata, and F. carica (Sabrutsia Rozovaya variety) that grow in the collection plots of the Nikitsky Botanical Gardens. In studied genotypes were assessed leaves tissue water cut, water deficit, moisture retaining ability, resistance to dehydration, proline content, peroxidase and polyphenol oxidase activity. It was defined that during the summer season physiological and biochemical parameters in the leaves of the studied species varied unequally. There was revealed the functional relation between the activity of peroxidase, polyphenol oxidase, proline content and the level of drought resistance of the studied species of the Ficus genus. The drought resistance of these varieties is most closely related to the proline content.
\end{abstract}

\section{Introduction}

The conditions of the Southern Coast of Crimea are conducive for cultivation a wide range of subtropical cultures including therophyllous plants of the Ficus genus. However frequent droughts during summer period have negative impact on their state. Because of this the

Drought resistance issue requires special consideration in which the water-retaining potential of leaf tissues and the ability to quickly restore physiological and biochemical processes after drought exposure play the main role. Scientific and practical objective of current importance is to determine the plants mechanisms of adaptation to complex effect of high temperatures and water stress. Antioxidant system that includes both specific redox enzymes (catalase, superoxide dismutase, and various oxidases: peroxidase, polyphenol oxidase, etc.) and low molecular weight non-protein antioxidants contributes significantly to stress factors resistance of plants $[1,2]$. The level of antioxidant protection and the ability of antioxidant system to react quickly on extreme conditions determine the plants

\footnotetext{
* Corresponding author: oksanagrebennikova@yandex.ru
} 
resistance to stress [3]. In light of this the study of redox enzymes activity and low molecular weight protective compounds content under the influence of negative factors is necessary to reveal the plant's adaptive capacity to stressful conditions. Hence the objective of our studies was to identify the functional relation between the peroxidase and polyphenol oxidase activity, proline content and the level of drought resistance of some therophyllous species of the Ficus genus.

\section{Materials and methods}

The next therophyllous species of the Ficus genus were chosen as the objects of our study: Ficus palmata Forsk., Ficus virgata Roxb. and Ficus carica L. (Sabrutsia Rozovaya variety) that grow in the collection plots of the Nikitsky Botanical Gardens.

Physiological and biochemical parameters in the leaves had been studied every month during the entire droughty period (May-August) at the following stages of the experiment: 1. complete water cut; 2. wilting (during 3-4 hours); 3. restoration of tissue turgor. The leaves tissue water cut was measured by the gravimetric method (by drying the weighed portions in thermostat at $105^{\circ} \mathrm{C}$ to constant weight); water deficit, water retaining capacity and resistance to dehydration - according to the classical methods [4]. The determination of proline content was conducted according to the modified methodic of Chinard using a ninhydrin reagent [5]. The activity of peroxidase was determined spectrophotometrically by the rate of the oxidation reaction of benzidine; the activity of polyphenol oxidase - in the presence of pyrocatechol and p-phenylenediamine. The experiments were conducted three times in repeat. The obtained data were processed using Microsoft Excel program.

\section{Results and discussion}

In May 2020 the leaves water content of the studied Ficus genus species was close to optimal and reached $96-98 \%$ of the total moisture capacity. The water deficit in tissues stayed in the range of $8-11 \%$. After 3 hours of wilting the studied plants lost from 14,5 to $19,0 \%$ of moisture that didn't exceed the sublethal level of water deficit in leaves of $F$. carica and $F$. palmata varieties. Due to this, the amount of the restored leaf surface area was $95-100 \%$. In the leaves of $F$. virgata species the turgidity was within $80 \%$. In June the water content decreased by 7,0-7,5\% comparing with the indices in May. A comparatively increased moisture deficit was observed in the leaves of $F$. virgata $(13 \%)$ (Table 1).

The variety Sabrutsia Rosovaya demonstrated minimal water deficit as well as in May. After 4 hours of wilting none of the genotypes demonstrated complete restoration of leaves turgor. The $F$. carica and $F$. palmata leaves had satisfactory level of reparation. The leaves of $F$. virgata species demonstrated weak moisture retaining ability. In July the leaves water content decreased by more $2-4 \%$ to the level of complete water content within $91-95 \%$. The water deficit varied in a wide range from $4.5 \%$ in the Sabrutsia Rozovaya to $17 \%$ in the $F$. virgata species. The lowest water retaining capacity and level of turgor recovery were observed in leaves of $F$. virgata. Other genotypes during the same period of time lost practically two timeless of moisture (15-17\%). However, after the water status was resumed the level of tissue reparation of the studied objects appeared to be insufficient. In August the water cut of leaves tissues practically did not vary, but as a result of moisture loss after 3 hours from 13 to $20 \%$, the amount of the leaf surface area that restored normal turgor did not exceed $94 \%$.

In conditions of a laboratory experiment it was established that at the start of the summer season (May) the proline content in the Ficus genus leaves in case of complete watering varied from $98 \mu \mathrm{g} / \mathrm{g}$ of $F$. virgata to $400 \mu \mathrm{g} / \mathrm{g}$ of $F$. palmata. During controlled 
dehydration the proline concentration of all Ficus genus representatives increased (by 19,0$34,7 \%$ ) and decreased (by 9,0-42,8\%) during resumption of water supply. The least proline content changes during the experiment were observed in leaves of Sabrutsia Rozovaya variety: the proline concentration of the leaves at watering in June was $121-179 \mu \mathrm{g} / \mathrm{g}$.; it increased during dehydration (by 17,4-37,4\%) and kept on rising at water supply restoration (by 14,6-37,5\%). In July the proline content of $F$. carica species (108-192 $\mu \mathrm{g} / \mathrm{g}$ at complete watering) increased during the wilting process (by 24,5-79,5\%) and decreased (by 16,3\%) after water supply restoration but continued to rise in $F$. virgata and $F$. palmata species (by 4,226,7\%). In August after wilting the proline content in the leaves of $F$. carica and $F$. palmata increased and decreased after restoration of turgidity (Fig. 1). In the leaves of $F$. virgata species the variability of this amino acid content was not significant.

Table 1. Water retaining and repairing ability of leaves of the studied Ficus genus species (summer season 2020)

\begin{tabular}{|c|c|c|c|c|c|c|c|c|}
\hline \multirow{2}{*}{ Genotype } & \multirow{2}{*}{$\begin{array}{c}\text { Water } \\
\text { content in } \\
\text { leaves, \% } \\
\text { from raw } \\
\text { mass }\end{array}$} & \multirow{2}{*}{$\begin{array}{l}\text { Water } \\
\text { content in } \\
\text { leaves, } \\
\text { complete } \\
\text { watering, \% } \\
\text { from raw } \\
\text { mass }\end{array}$} & \multirow{2}{*}{$\begin{array}{c}\text { Water } \\
\text { deficit } \\
\text { in } \\
\text { leaves, } \\
\%\end{array}$} & \multicolumn{4}{|c|}{$\begin{array}{c}\text { Water loss during wilting, } \\
\%\end{array}$} & \multirow{2}{*}{$\begin{array}{c}\text { Leaves } \\
\text { restored } \\
\text { turgor \% }\end{array}$} \\
\hline & & & & $1 \mathrm{hrs}$ & $2 \mathrm{hrs}$ & $3 \mathrm{hrs}$ & $4 \mathrm{hrs}$ & \\
\hline \multicolumn{8}{|c|}{ June } & \\
\hline F. carica & 71,7 & 75,3 & 4,7 & 10,9 & 11,2 & 12,8 & 18,2 & 82 \\
\hline F. virgata & 70,1 & 77,3 & 12,9 & 9,3 & 14,3 & 17,1 & 21,9 & 65 \\
\hline F. palmata & 69,4 & 73,8 & 9,6 & 4,7 & 8,7 & 11,6 & 17,4 & 80 \\
\hline \multicolumn{8}{|c|}{ July } & \\
\hline F. carica & 70,0 & 71,8 & 4,5 & 7,8 & 11,3 & 14,2 & 17,3 & 85 \\
\hline F. virgata & 66,3 & 71,6 & 17,0 & 10,7 & 15,8 & 22,4 & 27,7 & 75 \\
\hline F. palmata & 68,0 & 69,8 & 9,1 & 6,0 & 10,1 & 11,6 & 14,6 & 83 \\
\hline \multicolumn{8}{|c|}{ August } & \\
\hline F. carica & 69,5 & 71,66 & 5,4 & 5,8 & 9,9 & 13,4 & $*$ & 92 \\
\hline F. virgata & 67,4 & 71,70 & 17,5 & 7,6 & 14,2 & 20,1 & $*$ & 85 \\
\hline F. palmata & 68,2 & 68,92 & 8,9 & 5,9 & 10,6 & 15,1 & $*$ & 94 \\
\hline
\end{tabular}




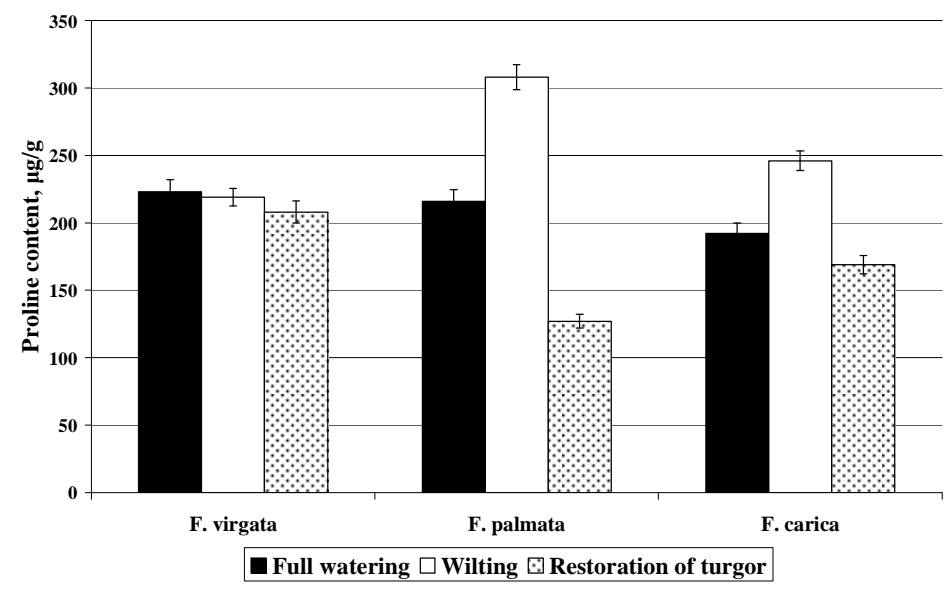

Fig.1. The proline content in the leaves of $F$. palmata, F. virgata and F. carica species in August (at various stages of the experiment on drought resistance)

As the result of the study of peroxidase $\left(0,016-0,031 \mathrm{cu} / \mathrm{g}^{*} \mathrm{~s}\right)$ and polyphenol oxidase functioning $(0,013-0,015 \mathrm{cu} / \mathrm{g})$ during controlled wilting of the Ficus genus leaves it was found out that at the end of May the activity of enzymes slightly increased at dehydration (up to $15,0 \%$ ) and decreased to the initial content after removing the stress exposure. In June the activity of peroxidase $(0,039-0,078 \mathrm{cu} / \mathrm{g} * \mathrm{~s})$ and polyphenol oxidase $(0,014-0,024$ $\left.\mathrm{cu} / \mathrm{g}^{*} \mathrm{~s}\right)$ in the leaves of Ficus species increased at dehydration and after stress remove. In July the dehydration of leaves entailed the enzymes activation. The turgidity restoration process was characterised by peroxidase activity decrease in the leaves of $F$. carica and $F$. palmata species and the subsequent rise of polyphenol oxidase activity in the leaves of all species. In August in dehydrated leaves the activity of enzymes increased and after the stress influence was removed the activity of peroxidase and polyphenol oxidase in the leaves of $F$. carica and $F$. palmata species (fig. 2,3 .) decreased. In the leaves of the $F$. virgata species the enzyme activity did not change significantly after removing the stress exposure.

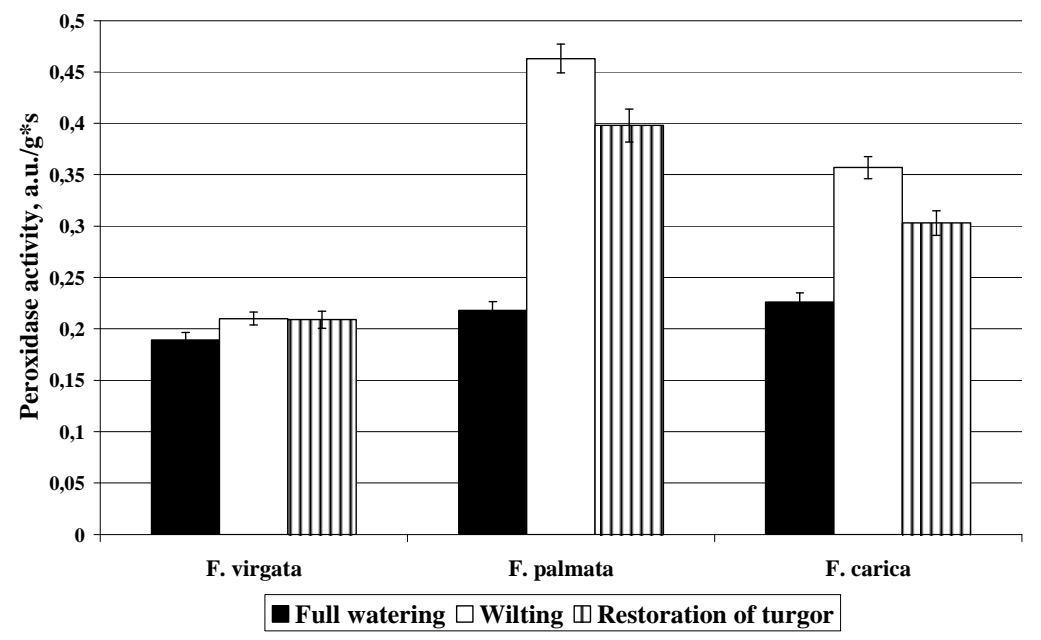

Fig. 2. The peroxidase activity in F. palmata, F. virgata and F. carica leaves in August (at various stages of the experiment on drought resistance) 


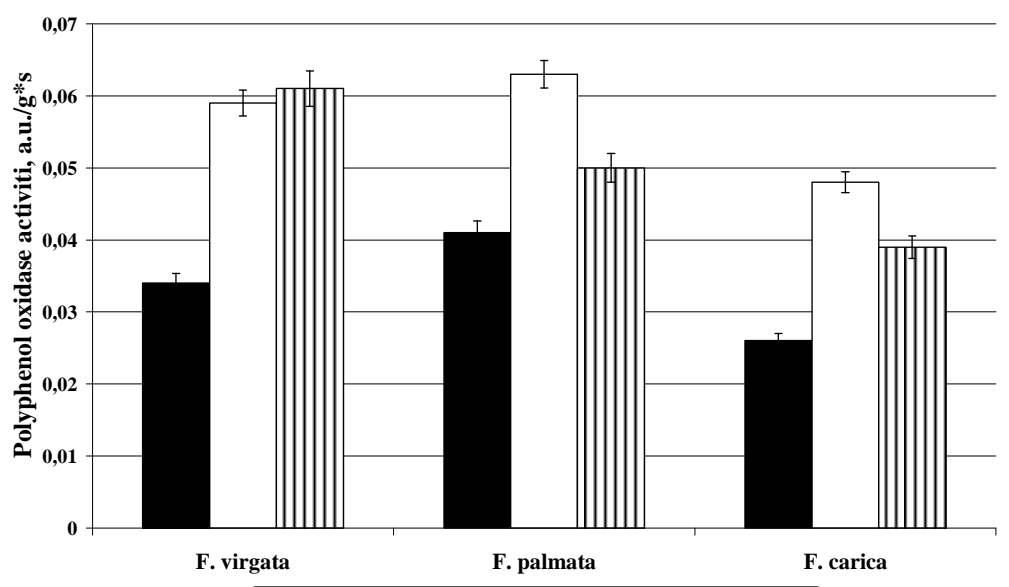

$\square$ Full watering $\square$ Wilting $\square$ Restoration of turgor

Fig. 3. The polyphenol oxidase activity in F. palmata, F. virgata and F. carica leaves in August (at various stages of experiment on drought resistance)

Processing the obtained data revealed that during summer season in spite of identical experiment conditions the different alterations of physiological and biochemical parameters took place in the leaves of studied genotypes. At the same time throughout the whole season the leaves of Sabrutsia Rozovaya variety demonstrated high moisture retaining ability, the maximum ability to repair tissues after dehydration and to restore biochemical parameters after removing stress exposure and, as a result, normalizing metabolic processes. Only after 5 hours of wilting in June after removing stress the leaves of this variety did not recover which indicates drought resistance. The leaves of $F$. palmata species differed by the best ability to retain moisture, demonstrated high ability to repair tissues after dehydration and satisfactory level of metabolic processes restore. The leaves of $F$. virgata species demonstrated the minimal water retaining capacity, level of turgor and metabolism recovery.

As the result of the research it was established that moisture loss in the leaves of studied genotypes causes the increase of proline content, rise of peroxidase and polyphenol oxidase activity that indicates involving these antioxidants into responses of $F$. carica, $F$. palmata and $F$. virgata species to moisture deficit. The obtained results demonstrate the relation between such biochemical parameters as peroxidase and polyphenol oxidase activity, proline content and the level of drought resistance of the studied Ficus genus species. The drought resistance of these species is most closely related to the proline content, and the least - to the polyphenol oxidase activity.

\section{References}

1. R. Mittler, Trends Plant Sci., 7 (2002)

2. N. Yadav, S. Sharma, Chem. Pharm. Res. J., 8 (5) (2016)

3. N. Suzuki, R. Mittler, Physiologia Plantarum, 126 (2006)

4. G. N. Eremeev, A. I. Lishchuk, Methodical instructions for selection of droughtresistant varieties and rootstocks of fruit plants. (Yalta, 1974)

5. V. K. Andriuschenko, V. V. Sayanova, A. A. Zhuchenko, Izvestiya AN MSSR, 4 (1981) 